\title{
Psychological team diversity and strategy implementation
}

Citation for published version (APA):

Boone, C. A. J. J., \& van Olffen, W. (2002). Psychological team diversity and strategy implementation. METEOR, Maastricht University School of Business and Economics. METEOR Research Memorandum No. 005 https://doi.org/10.26481/umamet.2002005

Document status and date:

Published: 01/01/2002

DOI:

10.26481/umamet.2002005

Document Version:

Publisher's PDF, also known as Version of record

\section{Please check the document version of this publication:}

- A submitted manuscript is the version of the article upon submission and before peer-review. There can be important differences between the submitted version and the official published version of record.

People interested in the research are advised to contact the author for the final version of the publication, or visit the DOI to the publisher's website.

- The final author version and the galley proof are versions of the publication after peer review.

- The final published version features the final layout of the paper including the volume, issue and page numbers.

Link to publication

\footnotetext{
General rights rights.

- You may freely distribute the URL identifying the publication in the public portal. please follow below link for the End User Agreement:

www.umlib.nl/taverne-license

Take down policy

If you believe that this document breaches copyright please contact us at:

repository@maastrichtuniversity.nl

providing details and we will investigate your claim.
}

Copyright and moral rights for the publications made accessible in the public portal are retained by the authors and/or other copyright owners and it is a condition of accessing publications that users recognise and abide by the legal requirements associated with these

- Users may download and print one copy of any publication from the public portal for the purpose of private study or research.

- You may not further distribute the material or use it for any profit-making activity or commercial gain

If the publication is distributed under the terms of Article $25 \mathrm{fa}$ of the Dutch Copyright Act, indicated by the "Taverne" license above, 


\title{
Psychological team diversity and strategy implementation: theoretical considerations and an experimental study
}

by

\author{
Christophe BOONE \\ Woody VAN OLFFEN*
}

\author{
Maastricht University \\ Department of Management Sciences \\ Organization Studies Group \\ PO BOX 616 \\ 6200 MD Maastricht \\ The Netherlands

$$
\begin{aligned}
& * \text { tel. }++31-43-3883880 \\
& \text { fax: }++31-43-3884877
\end{aligned}
$$ \\ e-mail: w.vanolffen@mw.unimaas.nl
}




\title{
Psychological team diversity and strategy implementation: theoretical considerations and an experimental study
}

\begin{abstract}
The overwhelming majority of team or group composition studies are restricted to analyzing the link between team demographics and the content of specific strategic choices. We argue that in order to make progress in this domain it is now time to broaden the approach by focusing on psychological team composition and issues of effective implementation. In addition, we propose a more sophisticated theoretical and methodological approach to the use of specific team composition measures. We conducted an experimental study in order to explore the potential of addressing these major limitations of past research. Specifically, we hypothesize on and analyze the relationship between the psychological composition of management teams (in terms of their members' control perceptions) and two aspects of effective strategy implementation:_meticulous planning and the configuration of consistent action patterns. We find that homogeneous 'internal' teams adapt their strategy-making behavior to the requirements of the environment, whereas homogeneous 'external' teams do not. As expected, mixed (i.e., heterogeneous) teams experienced most problems in effectively implementing their strategies. The findings provide support for the potential value of analyzing both psychological composition of decision making teams and strategy implementation issues. Furthermore, it underscores the importance of properly matching theoretical expectations and measurement methodology in multi-level research.
\end{abstract}

Key words: Strategy implementation, team composition, locus of control, methodology. 


\section{Psychological team diversity and strategy implementation: theoretical considerations and an experimental study}

\section{INTRODUCTION}

The past two decades have shown a surge in popular interest and publications on the functioning and alleged importance of teamwork for contemporary organizations (see e.g. Tjosvold, 1991; Katzenbach, 1993, 1998). This development was accompanied and partly preceded by many academic studies dealing with the consequences of diversity in teams (Milliken and Martins, 1996; Maznevski, 1994). To be sure, studying the effects of group diversity has a long history in social psychology, in particular in group dynamics (Lewin, 1948; 1951). Extending this line of research to the management realm, Hambrick and Mason (1984) argued that as an organization is a reflection of its top managers, studying the consequences of differences in the composition of top management teams (TMT) is a worthwhile endeavor. Their paper was very influential in the organizational sciences domain and it stimulated many research efforts into understanding the relationship between team composition, team functioning and organizational outcomes (see Finkelstein and Hambrick, 1996; and Van Olffen and Boone, 1998 for a review). The importance of their contribution resides in bringing back the individual into the predominantly macro-level organizational theory (Sörensen, 1999). In addition, as it links characteristics of human beings with organizational outcomes, such as strategy and performance, it has the potential to unify the increasingly disparate micro and macro ends of the field (Carroll and Harrison, 1998).

However, when taking stock of the empirical research inspired by Hambrick and Mason's call, one is left with a confusing picture. Except for the consistent negative relationship between tenure heterogeneity of team members and turnover (Carroll and Harrison, 1998), hardly any generality can be observed concerning the effect of different team compositions on organizational outcomes, such as strategy and performance. A review, for instance, of 12 representative team composition papers in which 54 relationships were tested shows that $52 \%$ of these test results were not significant (van Olffen, 1999). In addition, when significant findings are reported, effect sizes tend to be small. These many non-findings can mean two things: (1) management team composition does not really make a difference, or (2) methodological limitations of team studies impede finding general patterns. We think that before dismissing team composition as an important variable, it is 
essential to analyze the current methodological practice in team composition research first.

The main contribution of the present paper and the view defended here, is that progress can be made in the so called 'upper echelons' field by addressing some important methodological limitations of past research. We will also illustrate our point by presenting the findings of an exploratory experimental study into the relationship between the psychological composition of management teams and the construction of firm strategies. In our view there are three major limitations of past studies in this tradition ${ }^{1}$ namely: (1) an overemphasis on explaining strategy content at the expense of the micro-level process of strategy implementation (2) an almost exclusive focus on demographic characteristics of managers, and (3) an a-theoretical approach as far as the aggregation of individual characteristics to meaningful team-level variables is concerned. In order to show whether dealing with these limitations is a fruitful avenue for further research, we performed an experiment with managers in a business game setting in which we focus on the following points. First, we will explain effective strategy implementation as opposed to differences in the content of strategic choices. Second, we will pioneer a kind of within-team variation that has long been called for but rarely studied, namely psychological instead of demographic team composition (Milliken and Martins, 1996). Specifically, we chose to study team member's locus of control (Rotter, 1966) because of its proven relevance in areas that are logically related to aspects of sound implementation. Finally, we will argue that the standard methodological practice of computing the mean and some kind of variance measure to characterize the composition of teams is seldom justified and in most cases inadequate. Instead, we follow Chan's (1998) recommendation by explicating the theoretical underpinnings of using certain elementary composition rules. The purpose of this exercise is to arrive at a theoretically based, more meaningful classification of generic team types.

In the following section we address these limitations of standard practice in the upper echelons research tradition in detail. By doing so we are able to position our empirical contribution, designed to illustrate the potential of using new variables, methods and domains of investigation, more clearly. Subsequently, we present the theory and hypotheses related to our empirical study. In the methods section we will describe the experimental setup we used to test our team hypotheses. After presenting the results of our analyses, we discuss the findings. In closing we evaluate this study by mentioning limitations and opportunities for future work.

\footnotetext{
${ }^{1}$ Note that some of these limitations do not only apply to top management team research but also to team composition research in general, as will become clear below.
} 


\section{GENERAL BACKGROUND}

\section{Three limitations of previous research}

A first limitation of past team research in management is an almost exclusive focus on differences in the demographic composition of teams. The implicit assumption is that managers with certain demographic characteristics are rather homogeneous in holding certain attitudes, traits and values that presumably lead to a particular behavior. These attitudes and values themselves are, however, seldom measured and neither are their relationships with demographics. This practice obscures the exact mechanism by which demographics influence behavior and ultimately team functioning and organizational outcomes. We suspect that many non-findings in upper echelons studies (see Van Olffen \& Boone, 1998) are at least partly caused by this use of rather distant proxies like demographics for behavior. Thus, a focus on more fundamental behavioral tendencies rooted in personality seems warranted because these are more directly linked to behavior and provide a more valid measurement of values and attitudes than do demographic variables. In fact, Hambrick and Mason (1984) readily acknowledged this crucial point. When they presented their model and called for empirical research they made it very clear that "[i]t is doubtful that this research stream can progress far without greater attention to relevant literature in related fields, especially psychology and social psychology" (Hambrick and Mason, 1984: 203). Their emphasis on observable characteristics to start with, was inspired by rather pragmatic reasons like data availability and measurability. However, the growing need to use more psychological variables in upper echelons research is repeatedly stressed by researchers in the field. For instance, Hambrick et al. (1993: 402) state that "[e]ven though psychological factors (...) are of central significance to upper echelons theory, such phenomena are rarely studied or measured directly in empirical studies of top executives". Indeed, we know of no empirical management team study to date that has explicitly looked at the psychological composition of the team using validated personality inventories. In fact, this seems to be a void even in the broader social psychological field of intra team functioning and effectiveness (Schruijer and Vansina, 1997; Barrick et al., 1998). Note that this call for studying psychological diversity seems particularly important when firm strategies are studied from the perspective of microlevel actions taken by individuals and teams. As such, it seems a natural and appropriate level of analysis for studying strategy construction.

In the present paper we focus on the locus of control personality trait, which refers to individual differences in a generalized belief in internal versus external control of reinforcement (Rotter, 1966). People with an internal locus of control see themselves as active agents. They feel that 
they are masters of their fates and trust in their capacity to influence the environment. Conversely, those with an external locus of control see themselves as relatively passive agents and believe that the events in their lives are due to uncontrollable forces. We chose to study this particular trait because it indicates fundamental differences between individuals (Boone and De Brabander, 1993). Furthermore, control perceptions appear to be very salient in explaining effective management and individual managerial actions. Specifically, research into the relationship between Chief Executive Officer (CEO) locus of control and organizational performance consistently shows that firms led by internal CEOs perform better than firms headed by external CEOs, both in the short- as in the longrun (Miller and Toulouse, 1986a; Boone et al., 1996, 2000). Despite these results it is not yet very well understood why CEO locus of control matters so much.

It is here that we touch on the second limitation of previous research. Differences in strategic choice (i.e., content) tend to be overemphasized as the mediating mechanism between managerial characteristics and organizational performance. This occurs at the expense of strategy construction or implementation issues. On this, Lewin and Stephens (1994) observe that top management's role in shaping strategy has been discussed in the literature, but the CEO's motivation and ability to shape organization design as a means to implement strategy and to match the organization design with his or her management philosophy and style has been largely overlooked. To advance our understanding, future models of managerial decision making should not only focus on strategy choice but also on the processes associated with the effective implementation of these choices. In the case of CEO locus of control, Boone et al. (1996) in fact found indirect evidence that what really differentiates internal from external CEOs, is the former's ability to implement successfully whatever strategy. This is nicely underscored by the following general proposition of Lewin and Stephens (1994: 195) on the importance of top management locus of control: "CEOs with internal loci of control feel efficacious in controlling outcomes. Therefore, they are likely to believe in the concept of strategy, engage in strategic planning, implement the structures and processes for monitoring the environment that strategic planning entails, and restructure their organizations to fit the contingencies of their chosen strategies". In short: internals have better implementation skills. In this paper we wish to investigate aspects of this general proposition at the team level of analysis. That is, we will analyze how control perceptions in teams relate to the accuracy with which strategies are constructed through a process of careful planning and the configuration of consistent action patterns.

The final limitation is of a methodological nature. Team composition research is multilevel research in which data from a lower level, i.e. characteristics of individuals, are used to establish 
higher level constructs, i.e. team characteristics (Chan, 1998). It is essential to recognize that there are many different ways to derive higher level constructs from lower level data. As Barrick et al. (1998: 378) state, "there is not an established theoretical approach for proper aggregation of individual characteristics into team level constructs". However, in an insightful paper, Chan (1998) proposes a typology of composition models that specifies the functional relationship between constructs at different levels of analysis. He also shows that the specification of adequate composition models is a critical component of good multilevel research (Chan, 1998). In team research, and this is the third limitation, little attention is paid to the theoretical underpinnings of using certain elementary composition rules. That is, it is standard practice to aggregate data on individual characteristics, such as tenure, by computing the mean and the standard deviation or the coefficient of variation. In terms of Chan's typology, this implies that researchers implicitly use the additive and dispersion composition models, respectively. In the latter model, the meaning of the team construct derives from the dispersion or variance among lower level units and is operationalized with measures of within-group variance. In team research, social psychology theory on group functioning provides the basic background for hypothesizing on the effects of dispersion. Specifically, dispersion measures indicate the extent of heterogeneity among team members which is assumed to hamper cognitive and behavioral integration and therefore ultimately team effectiveness (Shaw, 1981, McCain et al., 1983, Wagner et al., 1984). The dispersion model has been used with success in several studies. For instance, empirical research consistently shows that heterogeneous teams with respect to tenure have higher turnover rates (Carroll and Harrison, 1998).

On the other hand, when averages are computed of lower-level data, one implicitly uses the additive model. In this model the higher level construct is just a summation of the lower level units regardless of the variance among these units. Our objection, however, is that the additive model is very inadequate for predicting group behavior because, theoretically, effects of the mean can only be expected when the dispersion is low. This is because hypotheses on the effect of the team means are invariably based on what is known at the individual level of analysis. An example will illustrate our point. Consider the following statement: 'A team with a high average age is unlikely to take risks because an old manager is equally unlikely to behave that way'. This type of reasoning, in which individual characteristics are directly extrapolated to the team level, is only justified when team members resemble each other. Take, for example, the following two teams, one consisting of members of age 20,40 and 60, and the other of 3 members of age 40 . Although both teams have the same mean, it is clear that theories based on the individual level of analysis can only inform us on the 
behavior of the second team but not of the first. This inadequate use of the additive composition model might explain the many inconsistent findings especially in the case of the effect of the mean of different demographic characteristics (Van Olffen, 1999). It is important to note that the problem is not solved by statistically controlling for dispersion when testing for the effect of the mean (as often happens) because it is the subtle interaction between mean and dispersion that counts. In Chan's terminology, the appropriate composition model for testing individual-level theories at the group level is the direct consensus model. In this model, aggregation of individual level data is only justified when consensus or homogeneity is present.

In the present study we will combine the direct consensus and dispersion model. This combination allows us to test and unravel the implications of both individual-level personality theories applied at the group level (by using the direct consensus model) and of social psychology theories of mixed group functioning (by using the dispersion model). For this purpose we distinguish three generic team types: two types of relatively homogeneous teams (i.e., internal and external teams) and one type, called heterogeneous teams, consisting of both internal and external members. By comparing homogeneous teams we can test team predictions based on individual personality theory. That is, a homogeneous internal team is likely to behave as an internal individual. Conversely, if externals dominate the team it will show more 'external-like' behavior. By comparing, heterogeneous (or what we call 'mixed') teams with both types of homogeneous teams we can test social psychology based hypotheses on the consequences of diversity. In our view, this approach is a better way to unravel the effects of different processes and in addition allows one to directly compare the relative functioning of different team types.

\section{THEORY AND HYPOTHESES}

Scattered evidence throughout the strategic management literature suggests that both management scholars and practitioners favor the issue of strategy formulation, in terms of both the content of and process leading to strategic choice. Much literature is devoted to the study of the content and/or ex ante process of strategy formulation; much less literature focuses on the ins and outs of the ex post implementation of the selected strategies. As said, this is also the case for management team composition research. The relative absence of implementation issues in the literature is not in balance with its importance for organizational performance in practice. It is widely accepted that several strategies may be viable in the same environment as long as managers are able to shape coherent configurations in which strategic choices, structures, systems 
and processes are carefully aligned (Miles and Snow, 1984; Snow and Hrebiniak, 1980). One might even conjecture that a superior implementation of a second-best strategy produces higher organizational performance than an inferior implementation of the first-best strategy (Boone et al., 1996). Given its large potential impact on organizational performance, we chose to focus on effective strategy implementation in this study. In addition, we have good reasons to believe that the composition of management teams, especially in terms of the locus of control of its members, has an important impact on effective strategy implementation. Before presenting our hypotheses, it is essential to shortly summarize the vast psychological literature into the behavioral consequences of locus of control.

This literature shows that internals generally perform better than externals in achievement related domains (Lefcourt, 1982; van Olffen, 1999). The reason is that the level of achievement basically depends on the extent to which three sets of specific achievement-related behaviors are performed (see Figure 1). First, an individual has to understand 'how the world works' by carefully directing his/her attention and making sense of the overwhelming number of stimuli which he/she encounters. Second, (s)he must engage in goal-directed behavior and be persistent despite setbacks. Intentions must therefore be translated into planned and consistent goal-directed behavior, from which a concerted action pattern results. Third, one has to be flexible enough to adapt behavior to the requirements of the situation when this is necessary.

\section{INSERT FIGURE 1 ABOUT HERE}

Note that individuals who believe in their own potency to master their environment (i.e., 'internals') are more likely to perform these achievement-related behaviors. In fact, a thorough review of the psychological literature (van Olffen, 1999) indeed reveals that internals are more inquisitive, are more persistent and goal-directed in achieving valued outcomes and behave less rigid than externals (Srull and Karabenick, 1975; Phares, 1976; Lefcourt, 1982). It is clear that especially the capacity of internals to act persistent and goal directed is very salient in the realm of effective strategy implementation (box II in Figure 1).

\section{Consensus model: homogeneous internal versus homogeneous external teams.}

The above mentioned findings of psychological studies and the very definition of the concept locus of control allows us to formulate the general proposition that internals are better straegy implementers than externals. It is likely that individuals who believe in their capacity to control their environment will be more motivated and persistent in trying to construct and implement a 
strategy that is believed to lead to success. They will make more conscious choices on how to deal with the various contingencies. These choices will be confidently and carefully implemented in order to maximize their potential success. Such behavior increases the likelihood of controlling the environmental contingencies, which is exactly what internals strive for. Externals, who tend to feel like pawns in a complex world, probably consider such efforts to be futile. These expectations concerning individual behavior based on personality theory can be extrapolated to the team-level under the condition that teams are relatively homogeneous, as explained in the previous section. So, homogeneous internal teams will be better strategy implementers than homogeneous external teams (in the remainder, the labels internal and external teams are used to indicate relatively homogeneous teams).

We focus on two aspects of effective strategy implementation in this study: planning quality and the extent to which strategies are internally and longitudinally consistent. As far as planning is concerned, hardly any research has been done into the relationship between locus of control and planning in a managerial context. An exception is the research of Miller and colleagues who found that internality is associated with the extent of self-reported planning for the future (Miller et al., 1982, Miller, 1983; Miller and Toulouse, 1986b). Unfortunately, these findings are based on CEO self-report assessments. This may have inflated the results due to common method variance (see Boone and De Brabander, 1997). Therefore, in the present study we wish to go beyond the mere subjective self-report measurement of planning aspects by readily observing the objective outcomes of effective planning activity. In addition, we focus on teams instead of single managers. As planning can be seen as a concerted effort to simultaneously optimize and control several aspects of a firm's functioning, internal teams may be expected to outperform external teams for two reasons. The first reason is simply that they believe and engage in planning more (as explained above). An additional reason is that internals are better able to cognitively process and integrate the different cues in a complex planning problem (Phares, 1976). In particular, internals are more sensitive to potentially relevant cues and crucial contingencies in ambiguous situations than externals. They are also better at retaining and integrating acquired information and generally seem to deal with tasks in a more organized fashion (Wolk and Ducette, 1974). This would qualify them better for performing complex tasks (Spector, 1982) like the planning task under study. Thus, based on personality theory the following hypothesis on the team level can be formulated with respect to planning quality: 
that of homogeneous external teams.

As internals are more likely to follow a planned course of action, we also expect to observe differences in the extent to which their actions are consistent, i.e. coordinated at each moment in and across time. Two types of strategic action consistency can therefore be distinguished: (1) the extent to which at a given moment in time choices are coordinated and integrated to form a logical, coherent pattern (coherence) and (2) the extent to which the choices are consistent over time (persistence). We predict internal teams to design more coherent strategies than external teams. This is because, as stated before, the whole concept of strategy as a consciously engineered action pattern to reach a goal has more appeal to internals than it has to externals (van Olffen, 1999). The latter will tend to expect little from this kind of coordination across actions and are thus more likely to show more incoherent and fragmented action patterns. Moreover, as in the case of planning, this coordination across actions requires an organized mode of attention, which internals possess more than externals (Lefcourt et al., 1968; Wolk and DuCette, 1974). For these reasons we expect internal teams to show greater coherence in their competitive repertoire (i.e., in their actions) than external teams.

Hypothesis 1b: $\quad$ Homogeneous internal teams will show greater coherence among actions than homogeneous external teams.

Internal teams may be expected to show more consistency in their actions over time as well. Based on their analysis of the situation and their motivated choice for a certain course, internals will show more (initial) commitment or persistence to their chosen competitive posture than externals. The reasonableness of this expectation is reflected in psychological studies showing internals' higher persistence in tasks even when confronted with intermediate setbacks (Srull and Karabenick, 1975; Karabenick and Srull, 1978). Externals will tend to be more volatile and whimsical, showing difficulty to hold on to a chosen course. Thus:

Hypothesis 1c: $\quad$ Homogeneous internal teams will show more action persistence than homogenous external teams.

\section{Dispersion model: mixed versus non-mixed teams.}

To hypothesize on differences between mixed (heterogeneous) and non-mixed (homogeneous 
internal and external) teams, we have to draw from the group dynamics literature (Shaw, 1981; Forsyth, 1990). This strand of research suggests that people differing on important attributes like age, tenure or personality may hold different frames of reference that hinder communication and cognitive and behavioral integration (McCain et al., 1983; Wagner et al., 1984; Zenger and Lawerence, 1989). These so-called process losses, in turn, increase the likelihood that conflicts, turnover (Wagner et al., 1984) and power struggles (Pfeffer, 1983) occur, attracting attention away from the immediate tasks of the group. The operational efficiency of diverse teams in performing their tasks is then threatened because much time and energy are required to overcome communication barriers and power games. To summarize, diversity has some clear drawbacks in relation to intra-group functioning. In general, it is clear that the implementation task of planning and aligning various and often contradictory elements of a company seems especially delicate in this respect. Applied to our study, we thus expect that the planning quality of mixed teams will be hampered by poor intra-group functioning.

Hypothesis 2a: $\quad$ The planning quality of mixed teams will be lower than that of non-mixed teams.

The argument against mixed teams on action coherence is similar as that discussed with planning quality above. Because of problems of achieving cognitive and behavioral integration, it is logical to expect that mixed teams will experience difficulties in forming a coherent set of behavior.

Hypothesis 2b: $\quad$ The coherence among actions of mixed teams will be lower than that of non-mixed teams.

Heightened misunderstanding and disagreement within mixed teams will tend to impede their ability to hold on to their strategic course of action as well.

Hypothesis 2c: $\quad$ The action persistence of mixed teams will be lower than that of nonmixed teams.

\section{Qualification: interaction with environmental dynamism.}

Finally, we wish to introduce an important moderating variable which is the level of environmental dynamism. We expect that the differences between the three generic team types will be more pronounced in dynamic than in stable environments. This prediction is consistent with both the consensus and the dispersion model. First, it follows from personality theory that personality traits, including locus of control, are much more important to predict behavior in 
weak versus strong situations (Weiss and Adler, 1984; Rotter, 1975). This is because in weak situations, which are characterized by uncertainty and ambiguity, there is latitude for interpretation of what happens in the individual's environment. Conversely, in strong situations, such as stable environments, clear guidelines for 'proper' behavior exist and therefore individual differences loose their power in predicting behavior (Miller and Toulouse, 1986b). Second, we also think that the problem of mixed teams to achieve cognitive and behavioral integration will be larger in dynamic as opposed to stable environments. Especially in uncertain and ambiguous environments in which no clear-cut answers exist, different individuals will tend to have different perceptions and opinions. This in turn raises the likelihood of conflict and communication barriers, reducing effective planning and consistent strategic behavior. Thus:

Hypothesis 3: $\quad$ The differences between the team types specified in hypotheses $1 a, 1 b, 1 c$, $2 a, 2 b, 2 c$ will be larger in dynamic than in stable environments.

\section{METHOD}

\section{Experimental setting}

The subjects of this study are participants of a large-scale management game played by 167 teams throughout Europe. The game is organized yearly by a Dutch commercial enterprise and is used by firms to train young managers as part of their management development programs. Because participating is all but cheap (about 5000 Dutch guilders, besides time consumption), firms are likely to select employees who will seriously play the game. As a result, the selected managers are probably highly motivated to satisfy the objectives of their employers, represented by their direct supervisors. Basically, this international management game is a realistic simulation of complex real-world competition. That is, each team of participants has to run a firm that faces multi-faceted competition in a number of markets. Here, we restrict the discussion of the game's nature to briefly outlining a number of the key aspects. [Details, can be found in the game's manual (MCC, 1993).]

The business environment created in the game is a highly realistic simulation of actual market conditions by reflecting both autonomous and induced market developments. The latter derive from the specific impact of firms' behavior on industry competition. Teams have to decide 
on strategy issues that cover all important business areas such as (investment in) production (capacity and quality), marketing (pricing, advertising and sales promotion), finance (capital budgeting), personnel (hiring, quality and layoff), intelligence and R\&D. Additionally, teams are allowed to cooperate with other firms in the industry so as to improve product quality and/or process efficiency. In each decision period, the choices have to be filled out on a special decision form that contains a total of over 30 decision categories (see Appendix A).

Teams compete in groups of five, a group being the game equivalent of an industry. This is where actual competition - with the other four industry members - takes place. The game is played in two rounds, I and II: the first round consists of six and the second round of seven socalled decision periods, 1 to 6/7. Each decision period lasts two weeks. At the end of each twoweek period, teams have to fax the aforementioned decision form to the game's management team, specifying their decisions for the upcoming period. After processing the decisions of the five competing companies, game management provides a summary of a team's results for the current period. This feedback involves a large range of relevant areas, including market shares, profit rates, and financial and stock positions. By the end of the six decision periods of round I, teams are ranked according to their so-called criterion score, being a composite measure of market share, profit and the projected sustainability of the company's results after the last playing period. This score therefore proxies short as well as long-run firm performance. On the basis of this ranking new groups (industries) of five teams are formed, by clustering strong and weak teams, to play round II. In doing so, teams compete against opponents of comparable strength in the second part of the game. After the end of the seven decision periods in round II, the top fifteen teams are invited to appear in the finals. This involves an intensive management game of one day, played at a conference center in The Netherlands. The winners are awarded a one-week business trip to Japan.

The fictive manufacturing company that each team manages, produces three different unspecified products, which are to be sold in three different markets (A, B and C, respectively). Market A, for product 1 , consists of a home market and an export market. Initial demand in market A (home and export) is about half market B's level. In the third period, demand for a new product, to be supplied to market C, starts to emerge. Initially, demand in this third market is low: about 25 and 13 percent of the initial demand levels in market A and B, respectively. Products produced for market B can also be dumped in a so-called 'white market' at a fixed price. Dumping, however, will generate lower demand for product B in the official market in the 
subsequent period. At the beginning of the two rounds, all five teams in an industry have equal market shares in market A and B (that is, 20\%). The share they obtain in the new product market $\mathrm{C}$ in period 3, depends on their second-period investment in preparing third-period market entry. Key market characteristics are summarized in Appendix B.

By paying for market research, firms (teams) can gain insight into the development of market demand for their products. Demand development in all markets generally follows a smooth trend over time. In each period, however, external shocks can create disturbances in demand. Teams are given notice of these shocks in advance. Firm's marketing efforts influence demand development for their product: for example, the average price level and total advertising outlays have a direct impact on demand in the current period and a limited lagged demand effect in the subsequent period. Also, credit facilities and investments in product improvement influence demand for a firm's products in later periods.

Because the game and the associated procedures are complex, the chances for misunderstanding by contestants were minimized by providing an elaborate manual, an information desk (reachable by telephone) and three short practicing rounds before the actual game started. We decided to restrict the analysis to the first-round game for two reasons. First, the re-composition of industries at the beginning of round II limits the opportunities to evaluate a team's performance over the whole game. Second, and more importantly, teams are not randomly assigned to industries in round II, which makes it impossible to disentangle team from industry effects. Specifically, each focal team is not competing against the same 'average' team in round II, implying that these data cannot be used to make sensible estimates of outcome differences between teams.

\section{Data collection and sample characteristics}

Data were collected through two routes. First, we received all team-level decisions and results from game management. Second, we mailed questionnaires to all team captains who agreed to distribute them among team members. The first questionnaire, A, consists of two parts. The first part contained questions relating to the members' backgrounds in terms of age, education, tenure, former work experience, team member familiarity and functional specialty. In the second part a validated psychological test measuring locus of control (Rotter, 1966) was administered. Three weeks after the first mailing, non-responding teams were mailed reminders and new questionnaires A. Finally, four weeks later captains of non-responding teams were contacted by 
phone. Three months after starting the game, team members were asked to individually fill out a questionnaire B regarding group processes such as decision rules, leadership behavior and relative participation.

In the end, 58 'complete' teams, out of the 167 that participated in the 1994 edition of the game (35.7\%), returned both questionnaires. A 'complete' team in our sample implies that all team members returned both questionnaires A and B. In sum, these teams consisted of 273 individuals. Based upon the results of the participation questions in questionnaire $\mathrm{B}$, we removed from our sample all individuals that had not actually participated according to at least two fellow team members: consequently, 21 cases were dropped, resulting in an effective sample of 252 individuals. Analysis of variance revealed that the sample is not significantly different from nonsampled teams on any of the average firm performance indicators i.e., market share, profit and sustainability (at $\mathrm{p}<.10$ ).

As the game originated in the Netherlands, most teams in our sample are Dutch. In fact, in the 1994 edition of the game $88 \%$ of the total number of teams was Dutch, the remainder coming from such diverse countries as Belgium, Germany, Greece, Hungary, Slovakia and Switzerland. Half of the respondents is employed in the service sector, predominantly professional business consulting or audit firms. With regard to team member characteristics, the sample includes (i) only a small minority of females (13.3\%), (ii) about $40 \%$ of team members with a university degree and (iii) members with an average age of about 33, ranging from 20 to 55.

\section{Measures and variables}

\section{Locus of control}

Individual control perceptions were measured with a Dutch translation of the well-known and widely used Rotter scale (Rotter, 1966). It contains 37 forced-choice items, 23 of those items measuring control expectancies and 14 being filler items. Respondents have to choose between an internal and an external control alternative. The following pair of statements provides an example: "Many times I feel that I have little influence over the things that happen to me" (external control alternative) and "It is impossible for me to believe that chance or luck plays an important role in my life" (internal control alternative). The total so-called 'Rotter score' is obtained by summing the number of external control alternatives chosen (with a minimum of 0 and a maximum of 23). As a result a high Rotter score corresponds to an external locus of control; a low score indicates an internal locus of control. The translated scale we used contains 
14 filler items to make the purpose of the test more obscure. The reliability and validity of this Dutch translation were repeatedly demonstrated (Boone et al., 1990; Boone, 1992; Boone and De Brabander, 1993; De Brabander et al., 1992). Non Dutch-speaking teams received a version that was translated in English and checked by native speakers. Coefficient alpha of the scale in our sample was .70, which concurs with internal consistencies reported by Rotter (1966) and Robinson and Shaver (1973). Alpha's value is well above the lower limits of acceptability (Nunnally, 1978).

\section{Team composition}

To capture the team's composition we followed a method quite different from the one usually employed in team studies. Conventionally, the arithmetic mean of a variable within a team is employed to characterize a team on a certain trait (e.g., age, tenure etc.) In addition, to assess whether a team is homogeneous or heterogeneous on that trait, the standard deviation or the coefficient of variation is calculated. As explained in Section 2, we think that these methods are inappropriate because the same mean may hide different standard deviations, and vice versa. So, teams with the same mean or standard deviation may be composed quite differently. For instance, teams with three relatively internal members (e.g., 3 times Rotter score 5) and one external outlier (e.g., Rotter score 15) yield an identical mean as teams with more evenly distributed Rotter scores (e.g., 2, 6, 11, 11). Yet, conceptually, these teams are very different. Only the former team could truly be labeled 'internal' in the spirit of our hypotheses and their underlying theories, whereas the latter is more heterogeneously composed. To arrive at a team classification that better fits with our purposes of measuring 'true' team internality (or externality) and which distinguishes generic team types unambiguously, we proceeded as follows. First, all individuals were classified as being internal or external based on their Rotter scores being either below or above the sample median of 10 . Second, team composition was evaluated by looking at the percentage of internals on the team. Teams characterized by more than 60 percent of their members being internals were classified as internal teams. Similarly, teams with less than 40 percent being internal are considered to be external teams. Finally, teams having a relatively balanced number of internals and externals were designated as mixed teams (i.e., all other teams). In doing so, we assured relative homogeneity of team members in the internal and external teams in a way that fits with the expected effects as stated in the hypotheses. It also yields relatively 
balanced subgroup counts appropriate for analyses. ${ }^{2}$ This procedure leads to the creation of 23 internal teams, 17 external teams and 18 mixed teams.

\section{Planning quality.}

Planning can be conceived of as an activity to simultaneously optimize and control different aspects of the environment in order to reach a goal. The planning activity of teams itself is unobservable in our research design. We can, however, measure its effectiveness, that is, the resulting quality of planning, which is adequate for our purpose. As shown in Appendix C, four important planning domains can be distinguished in the game: capacity planning (machines and personnel), input-output planning (raw material and end product stocks and production levels), sales planning and financial or liquidity planning. Both between and within these domains, the game consists of several interrelated processes that must be carefully monitored and planned to arrive at cost effective operations. It is clear that the planning quality of a team is high when it manages to effectively align processes in several domains simultaneously. We therefore developed an omnibus planning quality measure which is composed of seven planning effectiveness measures (A to $G$ ) related to the four central planning domains of the game. These seven effectiveness measures are described below.

\section{Capacity planning: personnel and machines utilization.}

In order to get most productivity out of investments in machines and personnel, it is important to minimize idle production capacity. The utilization of personnel and machine capacity was measured as the fraction of the total installed capacity that was used in each period to produce that period's production run i.e., (Total machines (personnel) capacity used) / (Total machine (personnel) capacity installed). This measure was averaged over the six playing periods. If in any period the volume of the intended production run is well matched to the available production capacity, capacity utilization is high and the best use is made of these resources. Thus capacity utilization of personnel $(A)$ and machines $(B)$ proxies the quality of capacity planning. If teams want to start a too high production volume, which cannot be produced with the available production capacity, game management interferes and decreases the volume of the intended production run proportionally until they fall within available capacity limits. ${ }^{3}$ As this interference

\footnotetext{
${ }^{2}$ We also used a more stringent cutoff point 30/70. This cutoff point yielded 14 internal, 11 external and 33 mixed teams. The 40/60 classification we used is clearly more balanced than this alternative. Note that the chosen cutoff point does not substantially change the results of the analyses reported here (see also footnote 8 for details).

${ }^{3}$ The same thing happens when insufficient raw materials are available.
} 
represents an instance of bad planning on the part of the team as well, we measured the average percentage of forced downward production adjustment i.e., ((Volume of forced production adjustment) / (Total planned production volume) * 100) as a third indicator $(C)$ of (bad) planning in this domain.

2. Input-output planning: raw material and end product stock increases.

The level of raw material stock at the end of period $t$ is determined (mainly) by the stock at the end of t-1 and the difference between raw materials inflow and outflow during period t. Raw materials flow in at the start of $\mathrm{t}$ when the raw material orders placed at $\mathrm{t}-1$ are received. Raw materials flow out, on the other hand, as they are used in producing period t's production run. Similarly, the level of the end product stock at the end of $t$ is determined by the end level of $t-1$ plus the balance between the inflow and outflow of end products during t. End products flow in as the production run of $t-1$ is delivered by the production department or when externally manufactured end products ordered in t-1 are delivered. Outflow of end products is driven by the sales in $\mathrm{t}$. The difficulty in managing both raw material and end product stock levels therefore lies in the planning of production, ordering and sales both in volumes and across time. As to the levels of these stocks, teams may prefer to set them lower or higher, possibly reflecting the amount of safety they want to build in. However, strong and consistently rising stocks ( $D$ and $E$ ) are an indication of faulty planning as either production or sales volumes were not properly matched. We therefore summed the volumes of stock rises that occurred between periods and used this total as an inverse indicator of planning quality. ${ }^{4}$

\section{Sales planning: no-sales.}

Sales planning involves the matching of production to stock and the demand for the product which is importantly influenced by the firm's marketing outlays. The question here is whether the firm is capable of serving the market in large enough quantities. If more units are produced than can be sold, stocks will (ceteris paribus) rise. This aspect of sales planning is therefore already captured in the above mentioned measure $E$. On the other hand, if firms cannot satisfy demand (i.e., if demand is higher than supply) so-called 'no-sales' occur. This is caused by the fact that either the firm has planned badly against the trend in generic demand or because its own relative marketing efforts have generated more specific demand than can be supplied to the market, that

\footnotetext{
${ }^{4}$ Stock-outs would be an alternative measure, but their effects are already captured elsewhere: possessing too few raw materials leads to game management interference by reducing teams' planned production levels (= measure C); endproduct shortage leads to no-sales (=measure F; see under 3).
} 
is: marketing and production are badly matched. In either case the total volume of no-sales $(F)$ over all periods can serve as a reverse indicator of the quality of these planning efforts.

4. Financial planning: cash shortage.

In order to pay current expenses, enough cash must be generated and secured. The amount of cash that firms hold can be taken as a safety stock just like the aforementioned end products and raw materials. If careful planning of the cash balance fails, however, firms may end up with a deficit $(G)$. In case this happens they have to borrow more money (i.e., get a so-called additional credit) at a higher interest rate or (in case the deficit is too large) they have to request suspension of payment. If they had anticipated the shortage they might have decided to borrow more in the preceding period. In any case, the total amount of cash shortage during the game inversely indicates the quality of liquidity planning. We measured this by calculating a team's cash position at the end of each period before the granting of additional credits. All cash deficits that occurred during the game are then summed to obtain our (inverse) measure of liquidity planning quality G.

The omnibus planning quality measure $(\mathrm{H})$ was computed by first reverse coding $\mathrm{C}$ to $\mathrm{G}$ to positively indicate planning quality and subsequently summing the standardized values of each of the seven planning effectiveness indicators. Note that this indicator $\mathrm{H}$ is an additive measure of planning quality which implies that reliability measures, such as Cronbach alpha, do not apply (see also Rotter, 1975).

\section{Action consistency}

Two types of consistency are mentioned in the hypotheses. First is the consistency between different actions at a given point in time, which we called action coherence. Second is the consistency of certain chosen postures over time; called action persistence. Operationalization of both types of action consistency will be described subsequently.

In determining action coherence, the use of a normative framework is inevitable. We tried, however, to remain as close as possible to quasi-objective common sense by distinguishing strategies on a single strategic continuum running from an emphasis on low cost to an emphasis on high value added. These extremes are defined as follows:

Low cost: $\quad$ Low prices with investments in cost reduction and a low emphasis on marketing expenses. 
High value added: Investments in marketing expenses sustained by high prices and a low emphasis on cost reductions.

Five variables were used to measure these strategic orientations: price level, promotion expenditures, product quality R\&D expenses, length of credit facilities granted to clients and efficiency R\&D expenses. Investments in efficiency lower variable cost and raw material usage per unit of production. Strategies take effect only in comparison with those of other competitors (i.e., other teams) in the industry. Therefore, in each period we measured the within-industry rank ( 1 to 5 ) of a team on each of these variables. A team scoring highest on a variable receives the highest rank: 1, a team scoring lowest receives the lowest ${ }^{5}$ rank i.e., 5. This means that a team following a high value added strategy should on average rank high (i.e., be either first or second) on price, promotion, quality and credit facilities, but low on efficiency expenses. A typical lowcost strategy would result in high ranks for efficiency outlays, but low ranks for price, credit facilities, promotion and quality. An example of the ranks associated typically with either a low cost or a high value added strategy are given in Table 1.

\section{INSERT TABLE 1 ABOUT HERE}

As said, we are not interested in the specific strategy that was followed, but in the consistency of the five action levels. It is clear that in coherent strategies the ranks of all variables, with the efficiency rank reverse coded, should be roughly identical. So, the sum of the absolute rank differences between the five variables constitutes an inverse measure of how coherent the actions are. To obtain a positive measure of consistency, we subtracted the summed rank differences from their theoretical maximum of 24 . Formally, our action consistency measure is as follows:

$$
\text { Action coherence }=24-\sum_{\mathrm{i}=1}^{4} \sum_{\mathrm{j}=\mathrm{i}+1}\left|\mathrm{R}_{\mathrm{i}}-\mathrm{R}_{\mathrm{j}}\right|
$$

In Table 1 we provide examples of the calculation of these measures for different teams. The action coherence measure was calculated in each period for every market separately. The coherence scores were then averaged over time to obtain mean action coherence on home market 1, export market 1, market 2 and market 3 (from period 3 onwards). Finally, an overall action coherence score was calculated by averaging the coherence scores on all four markets.

\footnotetext{
${ }^{5}$ Note that we use the term 'high rank' do denote a low rank figure! This may cause some confusion, but, as will become clear shortly, the specific coding order of ranks is of no importance to our ultimate purpose with this measure.
} 
Action persistence was operationalized as the stability in the rank of an action level over time. To assess this, for each market the standard deviation of ranks in period 1 to 6 was calculated for the level of prices, promotion, efficiency, product quality, sales group employment and credit facility granted. Because the standard deviation of ranks is in fact a measure of variability, all standard deviations were multiplied by -1 to obtain a measure that correlates positively with persistence. Next, these standard deviations were averaged over the four markets to obtain mean action persistence measures for every strategic action. These six action persistence measures were then again averaged to obtain an overall temporal consistency or action persistence measure. Thus, actions are considered to be persistent if, over time, teams keep occupying the same position on a certain action variable within their industry, that is: if rank variations are low. The overall coherence and persistence measures too are regarded as additive measures so that reliability estimates do not apply.

\section{Environmental dynamism}

The relevant competitive environment in which teams find themselves is their industry of five firms. Environmental dynamism must therefore be calculated at this industry level. This was done by looking at movements in teams' relative market positions and their pricing behavior. In this way we operationalized dynamism not only by referral to what teams experience (changing share positions) but also to an important aspect of what they and their competitors $d o$ to create such shifts, i.e., changing prices. Note that these changes in prices and market positions also breed the kind of uncertainty regarding the future that is inherent in dynamic environments. Our proxy of environmental dynamism was thus based on two measures: one related to market-share shifts over time and another measuring price-level turbulence. Following Murray (1989), we estimated dynamism in each market $i$ within an industry by taking the average of inter-period variabilities in individual firm j's shares $\left(D^{2} S_{i}\right)$ and prices $\left(D^{2} R_{i}\right)$. Formally, this is, for each market,

$$
\mathrm{DMS}_{\mathrm{i}}=1 / 5 \sum_{\mathrm{j}=1} \sigma\left(\mathrm{MS}_{\mathrm{i}}\right)_{\mathrm{j}} \quad \text { [Average five-firm market share variation in market i] }
$$

and

$$
\mathrm{DPR}_{\mathrm{i}}=1 / 5 \sum_{\mathrm{j}=1} \sigma\left(\mathrm{PR}_{\mathrm{i}}\right)_{\mathrm{j}}, \quad \text { [Average five-firm price variation in market i] }
$$


with $\sigma\left(\mathrm{MS}_{\mathrm{i}}\right)_{\mathrm{j}}$ and $\sigma\left(\mathrm{PR}_{\mathrm{i}}\right)_{\mathrm{j}}$ being the standard deviation of firm $\mathrm{j}$ 's market shares and price level in market $\mathrm{i}$ over periods 1 to 6 , respectively. Next, we obtained overall industry dynamism scores in market shares and price levels by computing the average of $\mathrm{DMS}_{\mathrm{i}}$ and $\mathrm{DPR}_{\mathrm{i}}$ over the markets. We performed a factor analysis on these two averages (DMS and DPR) in order to obtain a robust composite measure of industry dynamism. This produced a single-factor solution explaining 87 percent of total variance. The factor scores were split at the median to distinguish stable from dynamic industries. Thus, dynamic environments (i.e., industries) are characterized by uncertain and therefore unpredictable price-level fluctuations accompanied by large shifts in market share positions. The opposite holds for stable industries.

\section{RESULTS}

Table 2 reports total sample descriptives of effective strategy implementation measures. Breakdowns per team type and environmental conditions are shown in Table 3. Finally, Table 4 shows the results of ANOVAs with team type and environmental dynamism as factors and contrast analyses based on the means reported in Table 3. Note that, for the sake of parsimony, we only report on the overall measures of planning quality and action consistency. Separate analyses on the components of these overall measures, however, are almost identical and available from the authors upon request.

\section{INSERT TABLES 2, 3 AND 4 ABOUT HERE}

The ANOVA results reveal a very significant main effect and interaction effect (team type * environmental dynamism) on the overall planning quality measure (see upper part of Table 4). The other models with action coherence and persistence as the dependent variable show no significant main effects. However, the interaction effect is significant in both cases. Taken together these findings show that team composition in terms of locus of control of its member does matter and that its effect depends on the level of environmental dynamism. To test whether the differences between the team types follow our expectations as formulated in the hypotheses we computed appropriate contrasts between the different team types. These are reported in the lower part of Table 4.

\section{Consensus model: homogeneous internal versus homogeneous external teams}

We predicted that internal teams would achieve a higher planning quality, action coherence and persistence than external teams (Hypotheses 1a, b and c) especially in dynamic environments 
(Hypothesis 3). This implies that we expect to observe qualitatively the same but larger differences between internal and external teams in dynamic as opposed to stable environments (i.e., monotonic interactions). As far as planning quality is concerned we see that internal teams on average rank first (column 3 of Table 3), suggesting that internal teams generally plan best. However, this difference (.07) is not significant. Further analysis reveals that the expected difference only shows up in dynamic environments. That is, internal teams significantly plan better than external teams in dynamic environments (contrast $=2.15, \mathrm{p}<.05$ ). However, the difference is marginally significant in the opposite direction in stable environments (contrast $=-2.29, \mathrm{p}<.10$ ). Thus, in stable environments external teams seem to take the lead, which is not as predicted. This non-monotonic interaction is significant as shown by the interaction contrast reported in Table 4 (contrast $=4.44, p<.05)$.

The pattern of findings relating to the other two dependent variables (action coherence and persistence) resemble each other and are therefore discussed together. That is, in both cases we do not find a significant main effect. The action coherence and persistence of internal teams is not generally higher than that of external teams. As a result Hypotheses $1 \mathrm{~b}$ and $\mathrm{c}$ are not confirmed. We do, however, find interesting interaction effects. In stable environments, the action coherence and persistence of internal teams is significantly higher than that of external teams [contrasts are $1.72(\mathrm{p}<$ $.10)$ and $.14(p<.05)$ for coherence and persistence, respectively]. In dynamic environments, the opposite holds. That is, external teams now show highest action coherence $($ contrast $=-2.29, p<.05)$ and action persistence (contrast $=-.01$, ns). This switch in position in stable versus dynamic environments produces significant interaction contrasts $(-4.01, \mathrm{p}<.01$ for coherence; $-.15, \mathrm{p}<.05$ for persistence). Of course, these significant interaction contrasts do not provide evidence for a monotonic interaction of the kind predicted in Hypothesis 3, on the contrary. It appears that internal teams are more coherent and persistent in stable environments as opposed to dynamic environments; whereas exactly the opposite applies for external teams: they are less coherent and persistent in stable than in dynamic environments. We will return to this interesting finding in our discussion.

To summarize, we did not find supportive evidence for the simple, monotonic differences we predicted between internal and external teams on planning quality, action coherence and persistence. The interactions instead appeared to be non-monotonic, going against Hypotheses 1a, 1b, 1c and the qualification specified in Hypothesis 3. Apparently, the significant differences between internal and external teams crucially depend on the extent of environmental dynamism in a complex way. Possible explanations are offered in the discussion section. 


\section{Dispersion model: mixed versus non-mixed teams}

When comparing mixed versus non-mixed teams the findings are much more in line with our expectations, at least as far as planning quality and action coherence is concerned. That is, mixed teams take the lowest planning quality position both in stable as in dynamic environments [contrasts are $1.60(\mathrm{p}<.10)$ and $7.48(\mathrm{p}<.05)$ in stable and dynamic environments, respectively]. Consistent with Hypothesis 3, this difference appears to be significantly larger in dynamic environments (interaction contrast $=5.88, \mathrm{p}<.01$ ). Similarly, mixed teams compared to their non-mixed counterparts show lower action coherence in dynamic environments (contrast $=1.77, \mathrm{p}<.05)$. The difference, however, is not significant in stable environments, producing a marginally significant interaction contrast (contrast $=1.82, \mathrm{p}<.10$ ). Taken together, these findings are fully in line with Hypothesis 2a and provide partial support for Hypothesis 2b, i.e., as far as the results in dynamic environments are concerned. Hypothesis $2 \mathrm{c}$ must be rejected as no significant differences could be observed between mixed and non-mixed teams in both stable as dynamic environments.

\section{DISCUSSION}

We envisioned the following pattern of findings at the onset of the present study. Strategy implementation effectiveness (planning quality, action coherence and persistence) would be highest for internal teams followed by external teams and mixed teams in that order. We expected these differences between the three team types to become larger with increasing environmental dynamism. Although we found many significant differences in the present study, the pattern appeared to be much more complicated than we originally predicted and many of the interactions were nonmonotonic instead of monotonic. Only the behavior of mixed teams appeared to be at least in line with the spirit of our hypotheses. We indeed found evidence supporting the idea that mixed teams, presumably due to problems of achieving cognitive and behavioral integration, encounter difficulties in effective strategy implementation, especially in dynamic environments. Specifically, the planning quality of mixed teams was very poor compared to the other team types and they were the least able to design coherent strategies in dynamic environments.

When comparing internal with external teams, however, many significant but unexpected complex findings emerged which require some tentative ex post explanations. Recall that we mainly based our hypotheses on evidence reported in the psychological literature showing that internals are more goal-directed and persistent than externals (see box 2 of Figure 1). Maybe we overemphasized 
this difference between internals and externals at the expense of another one, i.e., the capacity of internals to adapt their behavior to the requirements of the environment (as shown in box 3 of Figure 1). Indeed, research has consistently shown that internals are much more sensitive and responsive to the environmental contingencies ruling success and failure (Lefcourt, 1982, van Olffen, 1999). If we look again at our findings through this lens, they do make sense.

The high (low) planning quality of internal teams (external teams) in dynamic but not in stable environments might follow from differences in the saliency of planning in different environments. Maybe internal teams are more motivated to plan carefully in dynamic environments because they then readily recognize the need for simultaneous attention to the different planning factors in such circumstances. Conversely, when many changes in the environment occur, the pessimistic view of external teams on the controllability of developments may be self-fulfilling as they let control slip. The idea that planning is more crucial to performance in dynamic environments is reflected in the fact that the correlation between teams' profitability and their overall planning quality in dynamic environments $(.74, \mathrm{p}<.000)$ is significantly higher $(\text { at } p<.05)^{6}$ than it is in stable environments $(.44, \mathrm{p}<.05)$. Given these differences, internal teams' behavior may be considered more appropriate or adapted than that of externals: when planning efforts are most needed, internal teams engage in it more and external teams less.

Concerning action coherence and persistence we found that internal teams were the most coherent and persistent team type in stable environments. In dynamic environments, external teams are much more coherent and all team types are equally persistent. Interestingly, coherence and persistence to a lesser extent is higher in dynamic than in stable environments among external teams. Precisely the opposite is true for internal teams. The explanation for this unexpected pattern of findings may again be found in a similar adaptation argument as we made for planning quality. When the environment is stable and predictable, policies can be configured rather strictly, whereas more dynamic circumstances may warrant partial adjustments on several policy aspects that render them less consistent but better suited for the prevailing circumstances. Maybe internal teams are more prone to show this kind of adaptive behavior than external teams and they do indeed seem to follow such an adaptive pattern of behavior, that is: they are most consistent in stable environments and considerably less so in dynamic environments. External teams show the opposite maladapted behavior: they get more coherent and persistent in dynamic as opposed to stable environments. Strict policies like the ones externals follow in dynamic environments may

\footnotetext{
${ }^{6}$ Fisher's $\mathrm{r}$ to $\mathrm{z}$ transformation is used for testing differences between correlations (see Cohen and Cohen, 1983:
} 
indicate a certain flight into rigidity, a withdrawal into strictness as a primitive defense against the need for changes that go against the 'wisdom' of a consistently configured policy. Unfortunately, this theoretical explanation is not reflected in the payoff of consistent behavior in the game. The overall correlations of action coherence and action persistence with profitability in the game are -.14 (ns) and -.12 (ns). So no overall relationship exists between consistent policies and profitability. The correlations in stable environments are -.28 (ns) and -.08 (ns) and in dynamic environments -.08 (ns) and -.16 (ns), respectively. We can therefore only conclude that although teams do seem to adjust in ways that are, at least intuitively, sensible and in accordance to their psychological make-up, this does not in fact pay off in our particular experimental research setting.

\section{CONCLUSION AND FUTURE RESEARCH}

The purpose of the present study was to extent the boundaries of TMT composition research by exploring the explanatory power of using new variables, methods and domains of investigation. We found that the locus of control composition of management teams, in interaction with environmental dynamism, explained a substantial part of the variance of three important variables in the realm of effective strategy implementation, i.e., planning quality (36\%), action coherence (17\%) and action persistence $(18 \%)$ in an experimental business game setting. As the proof of the pudding is in the eating, we think that the relatively large R-squares of the models presented in this paper underscore the potential of our approach. ${ }^{7}$ However, our findings together with the limitations of the present study also point to three more specific important avenues for further research.

First, our research made clear that differences between teams with respect to its locus of control make-up translate into differences in the construction of strategies, but mainly, and often only, in interaction with environmental dynamism. Many of the aspects of effective implementation we analysed yielded significant and interpretable findings. ${ }^{8}$ This underscores the validity of the locus of control trait as a determinant of (pro)active involvement in complex situations as it becomes

\footnotetext{
53-55).

${ }^{7}$ This point is all the more clear when we compare these results to those of analyses applying the 'conventional' approach (i.e., using the mean, while controlling for variance). Regression analyses show that mean locus of control plus its interaction with the dynamism factor explains only $3 \%, 4 \%$ and $10 \%$ of variance in planning quality, action coherence and action persistence, respectively. None of these effects reaches significance.

${ }^{8} \mathrm{We}$ checked the robustness of the interaction effects using the alternative cutoff point 30/70 (as mentioned in footnote 1). Our results are generally confirmed in this analysis. Only in case of persistence the 30-70 classification produced a weaker (insignificant) interaction result.
} 
manifest in planning and configuring consistent actions. However, several results appeared to be much more complex than predicted and forced us to propose a post hoc explanation for the regularities observed in the data. Specifically, an important hidden theme behind many of the results we encountered seems to be related to the adaptive capacity of internal teams. That is, internal teams' actions seem to be tailored to the situation they find themselves in. They plan when planning is most crucial and they define strict and looser strategies according to environmental pressures. External teams, on the other hand, do seem to follow purposive strategies, but often lack appropriateness. Maybe this is the ultimate reason why we observed that the profitability and market share of internal teams in the present game was much larger than the other team types, especially in dynamic environments (see Boone et al., 1998). Important for team research is that the superior performance of internal teams was not at all related to the specific content of the choices made. In fact, van Olffen (1999) found virtually no differences in strategic preferences, risk-taking or cooperative activity among the team types. Taken together we think that this theme of adaptation or adjustment, complementing issues of effective strategy implementation, should be of focal interest in future team research because, following Burgelman (1991), the experience and composition of teams might be a crucial determinant of the adaptive capacity and long-run success of organizations. Burgelman (1991) convincingly argued that successful companies are able to combine both efficiency and renewal at the same time. As locus of control is simultaneously related to goal-directed behavior (effective implementation) and the ability to change and adapt, team composition in terms of this trait might be a potential key factor in explaining differences in both the short- and long-run success of organizations.

Second, Boone et al. (1998) showed that the profitability of mixed teams was very poor and even negative in dynamic environments. This study provides a possible explanation for this finding as mixed teams had the lowest planning quality in dynamic environments. We assumed that the remarkable bad record of mixed teams on planning quality is due to the fact that in the planning task the integration of various aspects of the company into joint action is crucial. This integration may exactly be the Achilles' heel of mixed teams as it has been shown that team heterogeneity tends to undermine the social cohesion among team members (Pfeffer, 1983). It is clear, however, that more research is needed to measure and/or observe what exactly happens in mixed versus non-mixed teams. Almost no research exists that opens the black box of team composition. Future research should focus on the processes of interpersonal interaction within teams to understand why team composition is related to certain outcomes. Obviously, this requires more process-oriented and 
longitudinal research. Understanding team functioning in depth is very important for practical purposes because it allows one to detect the conditions under which team integration problems might be overcome. In this respect, it is worthwhile to investigate whether teams consisting of members that complement each other (i.e., mixed or heterogeneous teams) outperform any other team type when potential integration or cohesion problems can be solved.

Third, a short methodological note is warranted. As in all experimental research, objections as to the generalizibility of our results can be raised. We believe, however, that the combination of the complexity of the game design, the reward structure and the selection of participants by their superiors enhances the external validity of the findings, at least as far as decision making in (lower-level) management teams is concerned. It remains to be proven, however, to what extent the management teams studied inform us on the functioning of TMTs, the object of investigation in the upper echelons tradition. In this respect, it is, for instance, likely that TMTs will have more internal members on average compared to the management teams of the present study. This is because internality is associated with managerial effectiveness and consequently enhances promotion to the top. Thus, restriction in range with respect to the psychological composition of TMT teams, might increase the likelihood of non-findings in TMT settings. Note, however, that previous research reports relatively large and meaningful variation of locus of control scores even among CEOs (Boone et al., 1996, 2000; Miller and Toulouse, 1986a, 1986b) and among division managers of large Strategic Business Units (Govindarajan, 1989), suggesting that restriction in range is not that important. Taken together, we believe that given the relatively small effect sizes reported in past studies in the upper echelons tradition and the promising results of our illustrative experiment, this study at least points to the potential of (1) complementing the almost exclusive focus on strategic choice with attention for issues of strategy making and implementation, (2) focusing on the psychological instead of the demographic composition of teams, and (3) avoiding the mechanistic application of the mean and standard deviation to characterize different team types. This being said, the next step is of course to investigate whether the ideas presented in this paper survive when tested in a TMT field setting. This is what we actually plan to do now. 


\section{References}

Barrick, M.R., Stewart, G.L., Neubert, M.J. and Mount, M.K. (1998), Relating member ability and personality to work-team processes and team effectiveness, Journal of Applied Psychology, 83: 377-391.

Boone, C. (1992), Research into the relationship between managers' perception of control and strategy and performance of companies in the furniture industry, Antwerp: University of Antwerp.

Boone, C. and De Brabander, B. (1993), Generalized versus specific locus of control expectancies of chief executive officers, Strategic Management Journal, 14: 619-626.

Boone, C. and De Brabander, B. (1997), Self-reports and CEO locus of control research: a note, Organization Studies, 18: 949-971.

Boone, C., De Brabander, B.. and Hellemans, J. (2000), CEO locus of control and small firm performance: a note, Organization Studies, 21: 641-646..

Boone, C., De Brabander, B., Gerits, P. and Willemé, P. (1990), Relation of scores on Rotter's IE scale to short-team control expectancies and fatalism, Psychological Reports, 66: 1107-1111.

Boone, C., De Brabander, B. and van Witteloostuijn, A. (1996), CEO locus of control and small firm performance: an integrative framework and empirical test, Journal of Management Studies, 33: 667-699.

Boone, C., van Olffen, W. and Van Witteloostuijn, A. (1998), Psychological team make-up as a determinant of economic firm performance - an experimental study, Journal of Economic Psychology, 19: 43-73.

Burgelman, R. (1991), Intraorganizational ecology of strategy making and organizational adaptation: theory and field research, Organization Science, 2: 239-262.

Carroll, G. R., and Harrison, J.R. (1998), Organizational demography and culture: insights from a formal model and simulation, Administrative Science Quarterly, 43: 737-667.

Chan, D. (1998), Functional relations among constructs in the same content domain at different levels of analysis: a typology of composition models, Journal of Applied Psychology, 83: 234-246.

Cohen, J. and Cohen, P. (1983), Applied multiple regression/correlation analysis for the behavioral sciences, second edition, Hillsdale, New Jersey: Lawrence Erlbaum publishers.

De Brabander, B., Boone, C. and Gerits, P. (1992), Locus of control and cerebral asymmetry, Perceptual and Motor Skills, 75: 131-143.

Finkelstein, S. and Hambrick, D.C. (1996), Strategic leadership. Top executives and their effects on organizations, St. Paul, MN: West Publishing Company.

Forsyth, D.R. (1990), Group Dynamics, second edition, Brooks/Cole Publishing Company, Pacific Grove: California.

Govindarajan, V. (1989), Implementing competitive strategies at the business unit level: implications of matching managers to strategies, Strategic Management Journal, 10: 251-270.

Hambrick, D.C. and Mason, P.A. (1984), Upper echelons: the organization as a refection of its top managers, Academy of Management Review, 9: 193-206.

Hambrick, D.C., Geletkanycz, M.A. and Fredrickson, J.W. (1993), Top management commitment 
to the status quo: some tests of its determinants, Strategic Management Journal, 14: 401-418.

Karabenick, S.A and Srull, T.K. (1978), Effects of personality and situational variation in locus of control on cheating: determinants of the 'congruence effect', Journal of Personality, 46: 7295.

Katzenbach, J.R. (1993), The wisdom of teams: creating the high-performance organization, Harvard Business School Press.

Katzenbach. J.R. (1998), Teams at the top: unleashing the potential of both teams and individual leaders, Harvard Business School Press.

Lefcourt, H.M., Lewis, L.E. and Silverman, I.W. (1968), Internal versus external control of reinforcement and attention in decision making tasks, Journal of Personality, 36: 663-682.

Lefcourt, H.M. (1982), Locus of control: current trends in theory and research, Hillsdale, NJ: Lawrence Erlbaum.

Lewin, K. (1948), Resolving Social Conflicts, New York: Harper \& Row.

Lewin, K. (1951), Field Theory in the Social Sciences, New York: Harper \& Row.

Lewin, A.Y. and Stephens, C.U. (1994), CEO attitudes as determinants of organization design: an integrate model, Organization Studies, 15: 183-212.

Maznevski, M.L. (1994), Understanding our differences: performance in decision-making groups with diverse members, Human Relations, 47: 531-549.

MCC (1994), Management Game Manual, Amsterdam: MCC International b.v..

McCain, B.E., O'Reilly III, C.A. and Pfeffer, J. (1983), The effect of departmental demography on turnover: the case of a university, Academy of Management Journal, 26: 626-641.

Miles, R. and Snow, C.C. (1978), Organizational theory, structure and process, Tokyo: McGraw-Hill.

Miller, D. (1983), The correlates of entrepreneurship in three types of firms, Management Science, 29: 770-791.

Miller, D., Kets de Vries, M.R. and Toulouse, J.M. (1982), Top executive locus of control and its relationship to strategy-making, structure and environment, Academy of Management Journal, 25: $237-253$.

Miller, D. and Toulouse, J.M. (1986a), Chief executive personality and corporate strategy and structure in small firms, Management Science, 32: 1389-1409.

Miller, D. and Toulouse, J.M. (1986b), Strategy, structure, CEO personality and performance in small firms, American Journal of Small Business, 10: 47-62.

Milliken, F.J. and Martins, L.L. (1996), Searching for common threads: understanding the multiple effects of diversity in organizational groups, Academy of Management Review, 21: 402433.

Murray, A.I. (1989), Top management group heterogeneity and firm performance, Strategic Management Journal, 10: 125-141.

Nunnally, J.C. (1978), Psychometric theory, second edition, New York: McGraw-Hill.

Olffen van, W. (1999), Team level locus of control and competitive team behavior. An experimental study, Maastricht: Datawyse. 
Olffen van , W. and Boone, C. (1998), The confusing state of the art in top management composition research, NIBOR Research memorandum, Maastricht: Nibor.

Pfeffer, J. (1983), Organizational demography, Research in Organization Behavior, 5: 299-357.

Phares, E.J. (1976), Locus of control in personality, Morristown, NJ: General Learning Press.

Robinson, J.P. and Shaver, P.R. (1973), Measures of social psychological attitudes, Survey research center: Institute for Social Research.

Rotter, J.B. (1966), Generalized expectancies for internal versus external control of reinforcement, Psychological Monographs, entire nr. 609.

Rotter, J.B. (1975), Some problems and misconceptions related to the construct of internal versus external control of reinforcement, Journal of Consulting and Clinical Psychology, 43: 56-67.

Schruijer, S.G.L. and Vansina, L. (1997), An introduction to group diversity, European Journal of Work and Organizational Psychology, 6: 129-138.

Shaw, M.E. (1981), Group Dynamics: the Psychology of Small Group Behavior, third ed., New York: McGraw-Hill.

Snow, C.C. and Hrebiniak, L.G. (1980), Strategy, distinctive competence and organizational performance, Administrative Science Quarterly, 25: 317-336.

Sörensen, J. B. (1999), The ecology of organizational demography: managerial tenure distributions and organizational competition, Unpublished manuscript, University of Chicago.

Spector, P.E. (1982), Behavior in organizations as a function of employee's locus of control, Psychological Bulletin, 91: 482-497.

Srull, T.K. and Karabenick, S.A. (1975), Effects of personality-situation locus of control congruence, Journal of Personality and Social Psychology, 32: 617-628.

Tjosvold, D. (1991), Team organization: an enduring competitive advantage, Chicester: Wiley.

Wagner, W.G., Pfeffer, J. and O'Reilly III, C.A. (1984), Organizational demography and turnover in top management groups, Administrative Science Quarterly, 29: 74-92.

Weiss, H.M. and Adler, S. (1984), Personality and organizational behavior, Research in Organizational Behavior, 6: 1-50.

Wolk, S. and DuCette, J. (1974), Intentional performance and incidental learning as a function of personality and task dimensions, Journal of Personality and Social Psychology, 29: 90-101.

Zenger, T.D. and Lawrence, B.S. (1989), Organizational demography: the differential effects of age and tenure distributions on technical communication, Academy of Management Journal, 32: 353-376. 


\section{APPENDIX A \\ Decision categories}

\section{General decisions on...}

Buying of extra machines Hiring extra machines Buying of extra personnel Hiring extra personnel Borrowing Redemption of borrowings Use of supplier credit
Introduction of short time working Improvement of working climate Expansion of sales force Payment of dividend

Wage increases

Ordering of raw materials per product

\section{Production and marketing decisions on... Information on...}

Production volumes per product

Price per product

Deployment of sales force per product Promotion expenditures per product Product quality R\&D per product Efficiency R\&D per product Length of client credit term
Prices, stocks, production capacities, promotion outlays, product quality, sales force, working climate, market shares and wage levels of competitors.

Estimates of market demand, effectiveness of R\&D expenditures

\section{APPENDIX B}

\section{Product market characteristics}

\begin{tabular}{||l|l|l||}
\hline \hline Product & Market & Initial demand (number of products) \\
\hline 1 & A - Home & 100.000 \\
\hline & A - Export & 250.000 \\
\hline 2 & B - Official & 600.000 \\
\hline & B - "White" & Unlimited \\
\hline 3 & C & 80.000 \\
\hline
\end{tabular}




\section{APPENDIX C}

\section{Planning quality measures}

\begin{tabular}{|c|c|c|}
\hline Planning category & Planning measure & Calculation \\
\hline Capacity planning & $\begin{array}{l}\text { A. Average proportion of personnel capacity } \\
\text { utilisation } \\
\text { B. Average proportion of machine capacity } \\
\text { utilisation } \\
\text { C. Average proportion of forced downward } \\
\text { production adjustment }\end{array}$ & $\begin{array}{l}\Sigma \text { (Total personnel deployed / Total personnel } \\
\text { available) / } 6 \\
\Sigma \text { (Total machines deployed / Total machines } \\
\text { available) / } 6 \\
\sum \text { (Volume of forced downward adjustment / Total } \\
\text { planned production) / } 6\end{array}$ \\
\hline $\begin{array}{l}\text { Input-Output } \\
\text { planning }\end{array}$ & $\begin{array}{l}\text { D. Total raw materials (RM) stock rises } \\
\text { E. End product (EP) stock rises }\end{array}$ & 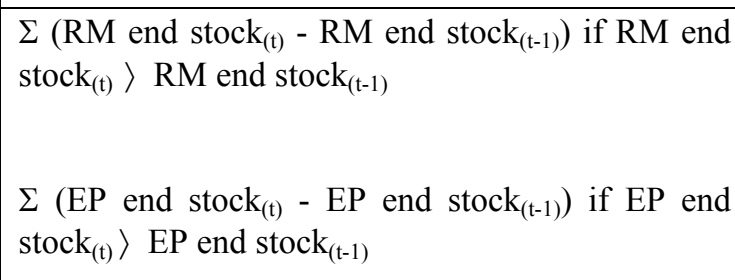 \\
\hline Sales planning & F. Total volume of no-sales & 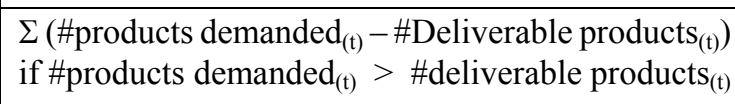 \\
\hline Financial planning & G. Total cash deficit & $\begin{array}{l}\Sigma\left(\text { Cash outflow }_{(t)}-\text { Cash inflow }_{(t)}\right) \text { if cash outflow } \\
>\text { cash inflow }_{(t)}\end{array}$ \\
\hline $\begin{array}{l}\text { Overall planning } \\
\text { quality }\end{array}$ & H. Simultaneous match & 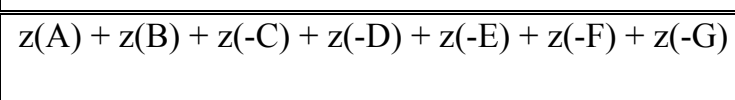 \\
\hline
\end{tabular}


FIGURE 1

Conceptual framework

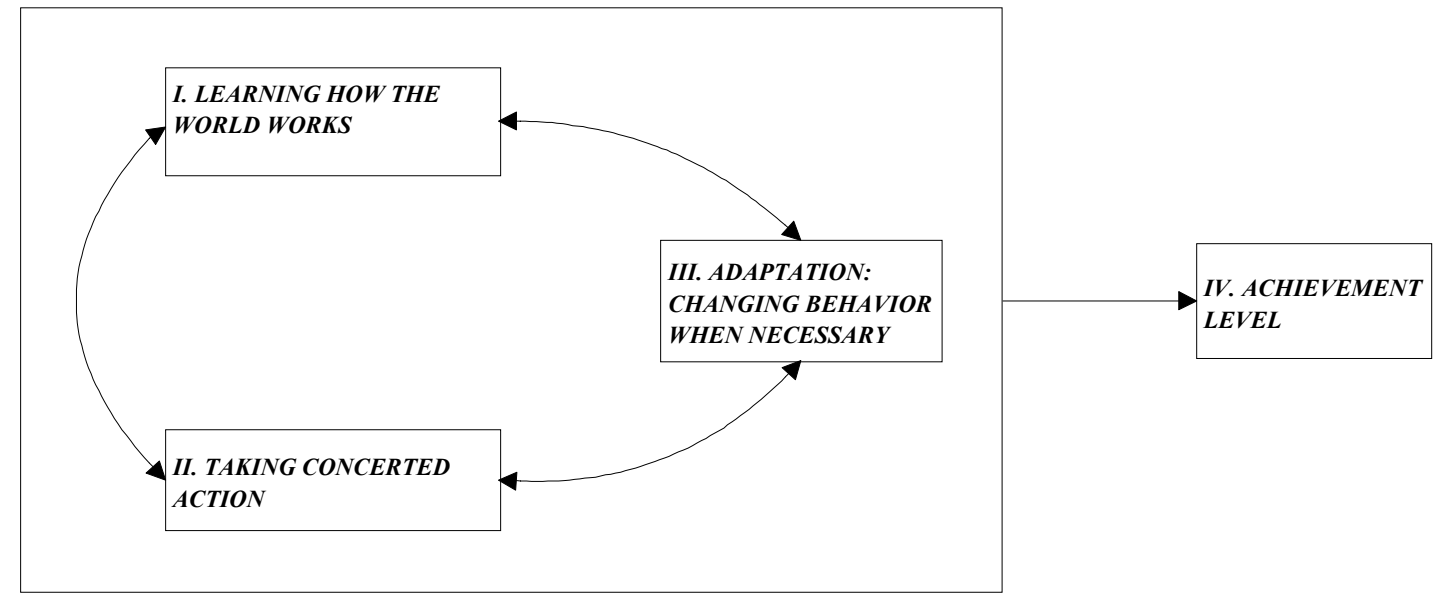


TABLE 1

Measuring action coherence: three hypothetical teams

\begin{tabular}{||l|l|l|l||}
\hline & Team 1 & Team 2 & Team 3 \\
\hline Strategy type & Low cost & High value added & Incoherent \\
\hline Price level rank $\left(\mathrm{R}_{1}\right)$ & 5 & 1 & 5 \\
Promotion expenditures rank $\left(\mathrm{R}_{2}\right)$ & 4 & 2 & 3 \\
Quality R\&D expenditures rank ( $\left.\mathrm{R}_{3}\right)$ & 4 & 2 & 1 \\
Credit facility rank $\left(\mathrm{R}_{4}\right)$ & 5 & 1 & 4 \\
(Efficiency expenses rank - originally) & $(1)$ & $(5)$ & $(2)$ \\
Efficiency expenses rank (reverse coded) & 5 & 1 & 4 \\
$\left(\mathrm{R}_{5}\right)$ & & & 18 \\
\hline (a) $\Sigma \Sigma\left|\mathrm{R}_{\mathrm{i}}-\mathrm{R}_{\mathrm{j}}\right|$ & 6 & 6 & 6 \\
(b) Action coherence (24- (a)) & 18 & 18 & \\
\hline
\end{tabular}


TABLE 2

Descriptives

Effective strategy implementation measures

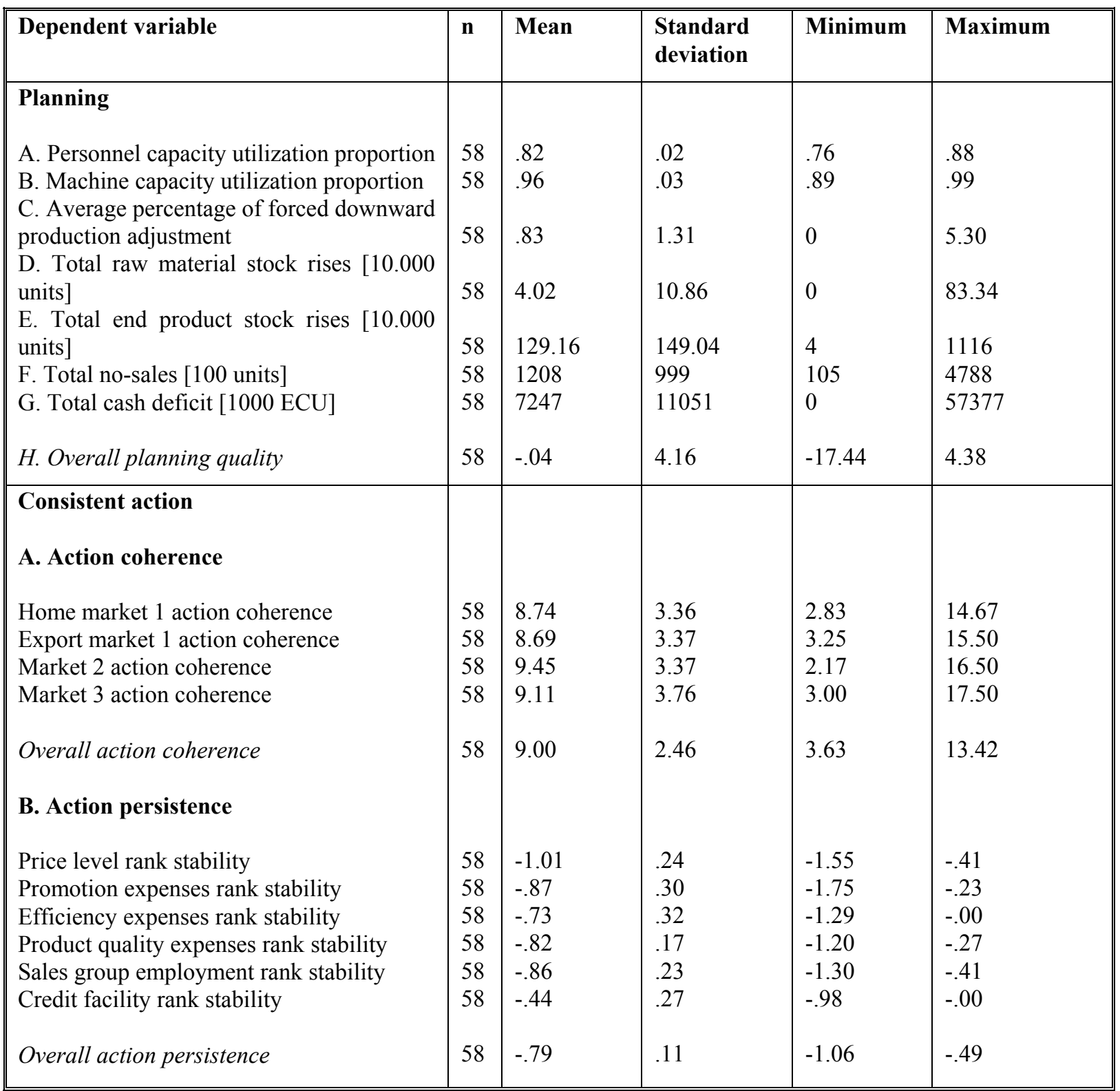


TABLE 3

Descriptives

Effective strategy implementation for different team types ${ }^{1}$

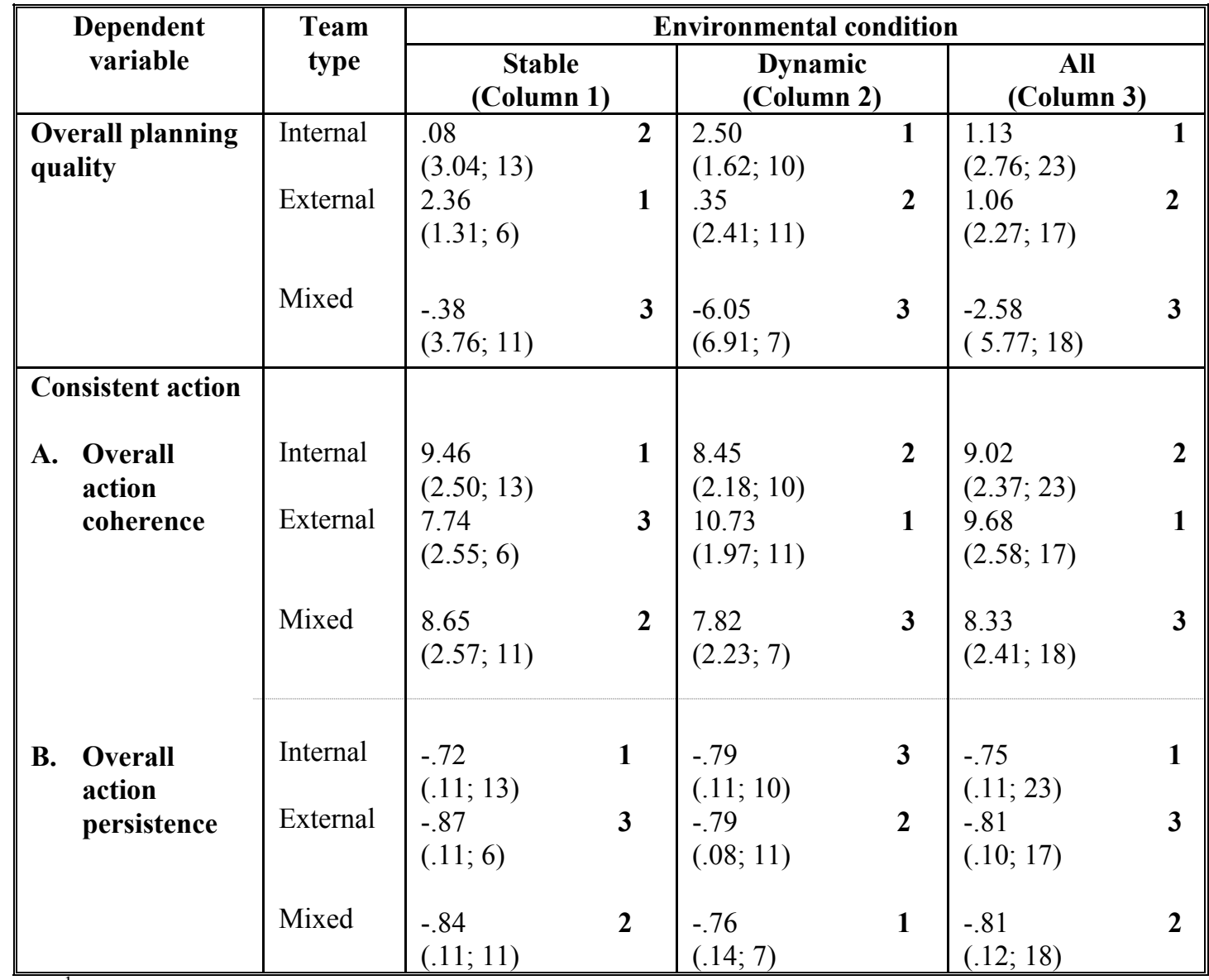

${ }^{1}$ Averages are reported. Standard deviation and number of observations are printed in parentheses. Rank orders are printed in bold ( $1=$ highest planning quality / coherence $/$ persistence; $3=$ lowest planning quality / coherence / persistence) 
TABLE 4

ANOVA and contrast analysis results

\begin{tabular}{|c|c|c|c|c|c|c|}
\hline & \multicolumn{6}{|c|}{ Dependent variables } \\
\hline & \multirow{2}{*}{\multicolumn{2}{|c|}{$\begin{array}{l}\text { Overall planning } \\
\text { quality }\end{array}$}} & \multicolumn{4}{|c|}{ Consistent action } \\
\hline & & & A. $\mathrm{O}$ & $\begin{array}{l}\text { ll action } \\
\text { rence }\end{array}$ & & $\begin{array}{l}\text { B. Overall action } \\
\text { persistence }\end{array}$ \\
\hline ANOVA factors & \multicolumn{2}{|c|}{ F-value ${ }^{1}$} & \multicolumn{2}{|c|}{ F-value $^{1}$} & \multicolumn{2}{|r|}{ F-value ${ }^{1}$} \\
\hline Team type & \multicolumn{2}{|c|}{$10.02(.00)$} & \multicolumn{2}{|c|}{$.81(.45)$} & \multicolumn{2}{|r|}{$1.96(.15)$} \\
\hline Environmental condition & \multicolumn{2}{|c|}{$3.42(.07)$} & \multicolumn{2}{|c|}{$.37(.56)$} & \multicolumn{2}{|r|}{$.99(.32)$} \\
\hline Interaction & \multicolumn{2}{|c|}{$6.70(.00)$} & \multicolumn{2}{|c|}{$3.94(.03)$} & \multicolumn{2}{|r|}{$3.22(.05)$} \\
\hline $\mathrm{R}^{2}$ & \multicolumn{2}{|c|}{.36} & \multicolumn{2}{|c|}{.17} & \multicolumn{2}{|r|}{.18} \\
\hline Environmental condition & Stable & Dynamic & Stable & Dynamic & Stable & Dynamic \\
\hline \multicolumn{7}{|l|}{ Main contrasts ${ }^{2}$} \\
\hline $\begin{array}{l}\text { Internal vs. External } \\
\text { teams (hypotheses 1a, 1b, } \\
\text { 1c) }\end{array}$ & $-2.29 \dagger$ & $2.15^{*}$ & $1.72 \dagger$ & $-2.29 *$ & $.14 * *$ & -.01 \\
\hline $\begin{array}{l}\text { Non-mixed vs. Mixed } \\
\text { teams (hypotheses 2a, } 2 b \text {, } \\
\text { 2c) }\end{array}$ & $1.60 \dagger$ & $7.48^{*}$ & -.05 & $1.77^{*}$ & .05 & -.03 \\
\hline Interaction contrasts & & & & & & \\
\hline $\begin{array}{l}\text { Internal vs. External } \\
\text { teams (hypothesis 3) }\end{array}$ & \multicolumn{2}{|l|}{$4.44^{*}$} & \multicolumn{2}{|l|}{$-4.01 * *$} & \multicolumn{2}{|l|}{$-.15^{*}$} \\
\hline $\begin{array}{l}\text { Non-mixed vs. Mixed } \\
\text { teams (hypothesis } 3 \text { ) }\end{array}$ & \multicolumn{2}{|l|}{$5.88 * *$} & \multicolumn{2}{|l|}{$1.82 \dagger$} & \multicolumn{2}{|l|}{-.08} \\
\hline
\end{tabular}

${ }^{1}$ Probability of $\mathrm{F}$ in parentheses. Significant F-values are printed in bold.

${ }^{2} \dagger=\mathrm{p}<.10, *=\mathrm{p}<.05, * *=\mathrm{p}<.01$ (one-tailed t-test). The interaction contrasts reported are the differences between the respective 'stable' and 'dynamic' columns above. 